\title{
Relationship Between Epicardial Fat volume on Cardiac CT and Atherosclerosis Severity in Three- Vessel Coronary Artery Disease: A Single-Center Cross-Sectional Study
}

\author{
Yu Sun \\ Northeastern University \\ Xiao-gang Li \\ General Hospital of Northern Theater Command \\ Kai Xu \\ General Hospital of Northern Theater Command \\ Jie Hou \\ Northeastern University \\ Hong-rui You
}

General Hospital of Northern Theater Command

Rong-rong Zhang

General Hospital of Northern Theater Command

Miao Qi

Northeastern University

Li-bo Zhang

General Hospital of Northern Theater Command

Li-sheng Xu

Northeastern University

\section{Stephen E. Greenwald}

Blizard Institute, Barts \& The London School of Medicine \& Dentistry, Queen Mary University of London

Ben-Qiang Yang ( $\square$ bqyang888@sina.com )

General Hospital of Northern Theater Command

\section{Research Article}

Keywords: Epicardial adipose tissue, Epicardial fat volume, Computed tomography angiography, Threevessel coronary artery disease

Posted Date: December 29th, 2021 
DOI: https://doi.org/10.21203/rs.3.rs-1152183/v1

License: (c) (1) This work is licensed under a Creative Commons Attribution 4.0 International License. Read Full License

Version of Record: A version of this preprint was published at BMC Cardiovascular Disorders on March 4th, 2022. See the published version at https://doi.org/10.1186/s12872-022-02527-7. 


\section{Abstract \\ Background}

The ideal treatment strategy for stable three-vessel coronary artery disease (CAD) patients are difficult to determine and for patients undergoing conservative treatment, imaging evidence of coronary atherosclerotic severity progression remains limited. Epicardial fat volume (EFV) on coronary CT angiography (CCTA) has been considered to be associated with coronary atherosclerosis. Therefore, this study aims to evaluate the relationship between EFV level and coronary atherosclerosis severity in threevessel CAD.

\section{Methods}

This retrospective study enrolled 252 consecutive patients with three-vessel CAD and 252 normal control group participants who underwent CCTA between January 2018 and December 2019. A semi-automatic method was developed for EFV quantification on CCTA images, standardized by body surface area. Coronary atherosclerosis severity was evaluated and scored by the number of coronary arteries with $\geq$ $50 \%$ stenosis on coronary angiography. Patients were subdivided into groups on the basis of lesion severity: mild (score $=3$ vessels, $n=85$ ), moderate ( 3.5 vessels $\leq$ score $<4$ vessels, $n=82$ ), and severe (4 vessels $\leq$ score $\leq 7$ vessels, $n=85$ ). The independent sample $t$-test, analysis of variance, and logistic regression analysis were used to evaluate the associations between EFV level and severity of coronary atherosclerosis.

\section{Results}

Compared with normal controls, three-vessel CAD patients had significantly higher EFV level $(65 \pm 22$ $\mathrm{mL} / \mathrm{m}^{2}$ vs. $\left.48 \pm 19 \mathrm{~mL} / \mathrm{m}^{2} ; P<0.001\right)$. In patients with three-vessel $C A D$, there was a progressive decline in EFV level as the score of coronary atherosclerosis severity increased, especially in those patients with a body mass index $(\mathrm{BMI}) \geq 25 \mathrm{~kg} / \mathrm{m}^{2}\left(75 \pm 21 \mathrm{~mL} / \mathrm{m}^{2} \mathrm{vs} .72 \pm 22 \mathrm{~mL} / \mathrm{m}^{2} \mathrm{vs} .62 \pm 17 \mathrm{~mL} / \mathrm{m}^{2} ; P<0.05\right)$. Multivariable regression analysis showed that both BMI (OR: 3.40, 95\% Cl: $2.00-5.78, P<0.001)$ and the score of coronary atherosclerosis severity $(O R: 0.49,95 \% \mathrm{Cl}: 0.26-0.93, P<0.05)$ were independently related to the change of EFV level.

\section{Conclusion}

Three-vessel CAD patients do have higher EFV level than the normal controls. While, there may be an inverse relationship between EFV level and the severity of coronary atherosclerosis in patients with threevessel CAD. 


\section{Background}

Patients suffering from three-vessel coronary artery disease (CAD) often have long-standing and complex coronary atherosclerosis and are at an increased risk of adverse cardiovascular events (1). Many randomized clinical trials results have revealed no significant differences in survival benefit between the two most widely used treatment, namely percutaneous coronary intervention and coronary artery bypass grafting, for the therapy of multivessel CAD patients (2-4). Recently, another multicenter randomized trial reported that, in stable CAD, there was no evidence that an initial invasive strategy reduced the risk of adverse cardiovascular events in comparison to medical therapy alone (5). Therefore, it is difficult to make the best choice of treatment strategy for stable three-vessel CAD patients. For patients who have undergone initial conservative treatment, evaluation of coronary atherosclerotic severity and assessment of its progression are in great demand, as an important aid in deciding further treatment, such as adjustment of drug dose or the ideal timing of invasive strategies.

Epicardial adipose tissue is a type of visceral fat that is located between the surface of the myocardium and the visceral pericardial layer. By secreting a large variety of bioactive molecules, it can modulate vascular inflammation via paracrine signaling mechanisms which, in turn contribute to the development of coronary atherosclerosis and the destabilization of existing atherosclerotic lesions (6). Many clinical studies have reported that the epicardial fat volume (EFV) using coronary CT angiography (CCTA) is associated with the presence and severity of coronary atherosclerosis and with the characteristics of atherosclerotic plaques (7-9). Measuring the volume of epicardial fat has been considered as a potential imaging biomarker of disease progression and response to treatment (10). However, clinical evidence of the relationship between EFV level and coronary atherosclerosis severity in three-vessel CAD patients remains limited, except for that arising from subgroup analysis in previously reported literature (11).

Threrfore, in the present study, we sought to investigate the relationship between EFV level assessed with CCTA and coronary atherosclerosis severity in three-vessel CAD.

\section{Methods}

\section{Study population}

In this single-center retrospective cross-sectional study, between 1 January 2018 and 31 December 2019, 1608 consecutive patients who underwent CCTA scanning in our hospital and had CCTA-based diagnosis of three-vessel CAD were initially included. Patients with previous percutaneous coronary intervention ( $\mathrm{n}=$ $147)$ or coronary artery bypass grafting $(n=297)$, pericardial effusion $(n=38)$, coronary anomalies $(n=$ 187), malignant chest tumor $(n=12)$, or systemic autoimmune disease $(n=3)$ were excluded. A further 418 patients without invasive coronary angiography (ICA) data were excluded. Patients with ICAconfirmed one- $(n=39)$ and two-vessel $(n=215)$ CAD were also excluded. Finally, 252 consecutive patients with ICA-confirmed three-vessel CAD were enrolled (Figure 1). The time interval between CCTA imaging and ICA operating of all patients was $(37 \pm 15)$ days. Three-vessel CAD was defined as $\geq 50 \%$ 
luminal diameter stenosis present in three main epicardial coronary arteries on the ICA data, including the left anterior descending artery, left circumflex, and right coronary artery, with or without the left main artery involvement.

For the normal control group, 252 age-, gender- and body mass index (BMI)-matched subjects were selected. They underwent CCTA because of chest pain from January 2018 to December 2019 and all had negative coronary atherosclerosis and no known cardiovascular disease.

\section{Cardiovascular risk factors and clinical data}

Demographic characteristics and clinical data (summarized in Table 1) were collected for all patients, including BMI, smoking history, hypertension, dyslipidemia, diabetes mellitus and family history of CAD. In addition, measures of left ventricular (LV) function assessed with transthoracic echocardiography were obtained from the hospital records. These included LV end-diastolic diameter, LV ejection fraction (LVEF), and the ratio of diastolic mitral inflow velocity $E$ peak and A peak $(E / A)$. Coronary collateral circulation status and SYNTAX score assessed with ICA data were also collected. 
Table 1

Basic characteristics and clinical data of study population

\begin{tabular}{|c|c|c|c|c|c|}
\hline \multirow[t]{2}{*}{ Variables } & \multirow{2}{*}{$\begin{array}{l}\text { Normal } \\
\text { control } \\
(n=252)\end{array}$} & \multicolumn{3}{|c|}{ Three-vessel CAD patients* } & \multirow[t]{2}{*}{$P$-value } \\
\hline & & $\begin{array}{l}\text { All } \\
\text { patients } \\
(n=252)\end{array}$ & $\begin{array}{l}\text { Low EFV level } \\
(<118 \mathrm{ml}, \mathrm{n}= \\
125)\end{array}$ & $\begin{array}{l}\text { High EFV level } \\
(\geq 118 \mathrm{ml}, \mathrm{n}= \\
127)\end{array}$ & \\
\hline $\mathrm{EFV}(\mathrm{ml})$ & $89 \pm 32$ & $120 \pm 42$ & $86 \pm 21$ & $154 \pm 29$ & $\begin{array}{l}< \\
0.001^{\#}\end{array}$ \\
\hline $\mathrm{EFV} / \mathrm{BSA}\left(\mathrm{mL} / \mathrm{m}^{2}\right)$ & $48 \pm 19$ & $65 \pm 22$ & $49 \pm 12$ & $82 \pm 16$ & $\begin{array}{l}< \\
0.001^{\#}\end{array}$ \\
\hline Epicardial FAI (HU) & $-84 \pm 9$ & $-81 \pm 5$ & $-78 \pm 4$ & $-84 \pm 4$ & $\begin{array}{l}< \\
0.001^{\#}\end{array}$ \\
\hline \multicolumn{6}{|c|}{ Cardiovascular risk factors } \\
\hline Age (y) & $61 \pm 8$ & $61 \pm 8$ & $61 \pm 9$ & $62 \pm 7$ & 0.163 \\
\hline Male sex, n (\%) & $193(77)$ & $193(77)$ & $93(74)$ & $100(79)$ & 0.416 \\
\hline $\mathrm{BMI}\left(\mathrm{kg} / \mathrm{m}^{2}\right)$ & $25 \pm 3$ & $25 \pm 3$ & $24 \pm 3$ & $26 \pm 3$ & $<0.001$ \\
\hline Smoking, n (\%) & $37(19)$ & $125(50)$ & $60(48)$ & $65(51)$ & 0.614 \\
\hline Hypertension, n (\%) & $0(0)$ & $179(71)$ & $85(68)$ & $94(74)$ & 0.293 \\
\hline Dyslipidemia, n (\%) & $0(0)$ & $45(19)$ & $21(17)$ & $24(19)$ & 0.664 \\
\hline Diabetes, n (\%) & $0(0)$ & $104(41)$ & $48(38)$ & $56(44)$ & 0.359 \\
\hline $\begin{array}{l}\text { CAD family history, } \\
\mathrm{n}(\%)\end{array}$ & $0(0)$ & $29(12)$ & $17(14)$ & $12(9)$ & 0.302 \\
\hline \multicolumn{6}{|c|}{ LV functional parameters } \\
\hline LV diameter (mm) & $48 \pm 3.8$ & $48 \pm 4.3$ & $48 \pm 4.5$ & $49 \pm 4.0$ & 0.023 \\
\hline LVEF (\%) & $61 \pm 5.0$ & $60 \pm 6.0$ & $60 \pm 6.4$ & $60 \pm 5.6$ & 0.911 \\
\hline $\mathrm{E} / \mathrm{A}$ & $1.6 \pm 0.3$ & $1.3 \pm 0.4$ & $1.2 \pm 0.4$ & $1.3 \pm 0.4$ & 0.056 \\
\hline
\end{tabular}

* Patients were divided into two subgroups according to median EFV level (118 ml).

\# $P$-values refer to the comparison between three-vessel CAD patients and normal controls. The remaining $P$-values refer to comparisons between the low and high EFV level subgroups of the CAD patients.

$\mathrm{CAD}$, coronary artery disease; EFV, epicardial fat volume; BSA, body surface area; $F A l$, fat attenuation index; BMI, body mass index; LV, left ventricular; EF, ejection fraction; $C C C$, coronary collateral circulation. 


\begin{tabular}{|c|c|c|c|c|c|}
\hline \multirow[t]{2}{*}{ Variables } & \multirow{2}{*}{$\begin{array}{l}\text { Normal } \\
\text { control } \\
(n=252)\end{array}$} & \multicolumn{3}{|c|}{ Three-vessel CAD patients* } & \multirow[t]{2}{*}{$P$-value } \\
\hline & & $\begin{array}{l}\text { All } \\
\text { patients } \\
(n=252)\end{array}$ & $\begin{array}{l}\text { Low EFV level } \\
(<118 \mathrm{ml}, \mathrm{n}= \\
125)\end{array}$ & $\begin{array}{l}\text { High EFV level } \\
(\geq 118 \mathrm{ml}, \mathrm{n}= \\
127)\end{array}$ & \\
\hline \multicolumn{6}{|c|}{ Invasive coronary angiography } \\
\hline CCC status, n (\%) & NA & $78(31)$ & $40(32)$ & $38(30)$ & 0.721 \\
\hline SYNTAX score & NA & $\begin{array}{l}29(23, \\
36)\end{array}$ & $30(23,36)$ & $29(23,35)$ & 0.793 \\
\hline \multicolumn{6}{|c|}{${ }^{*}$ Patients were divided into two subgroups according to median EFV level (118 ml). } \\
\hline \multicolumn{6}{|c|}{$\begin{array}{l}{ }^{\#} P \text {-values refer to the comparison between three-vessel CAD patients and normal controls. The } \\
\text { remaining } P \text {-values refer to comparisons between the low and high EFV level subgroups of the CAD } \\
\text { patients. }\end{array}$} \\
\hline \multicolumn{6}{|c|}{$\begin{array}{l}\text { CAD, coronary artery disease; EFV, epicardial fat volume; BSA, body surface area; FAl, fat attenuation } \\
\text { index; BMI, body mass index; LV, left ventricular; EF, ejection fraction; CCC, coronary collateral } \\
\text { circulation. }\end{array}$} \\
\hline
\end{tabular}

\section{CCTA data acquisition}

CCTA was performed using a 256-slice CT scanner (Brilliance CT, Philips Medical Systems, Cleveland, USA). Detailed scanning parameters were listed as follows: tube voltage, $120 \mathrm{kVp}$; detector collimation, $128 \times 0.625 \mathrm{~mm}$; pitch, 0.16 ; rotation time, $0.27 \mathrm{~s}$; slice thickness, $0.9 \mathrm{~mm}$; section increment, $0.45 \mathrm{~mm}$. Tube current was set using the ECG-based tube current modulation technique. About $60-70 \mathrm{ml}$ of iodine contrast agent was injected at a rate of $4.5-5.5 \mathrm{ml} / \mathrm{s}$ via a high-pressure injector, followed by a 20-30 ml flush of saline at the same rate. A prospective ECG-gated CCTA was triggered using a bolus tracking technique with a trigger threshold of 100 Hounsfield units $(\mathrm{HU})$ in the descending aorta. The mean estimated effective radiation dose of the CCTA scan was $(4.6 \pm 1.2) \mathrm{mSv}$.

\section{EFV level and epicardial FAI measurement}

EFV level quantification was quantified on axial CCTA images at $75 \%$ of the R-R interval. A semiautomatic method was developed for segmenting the pericardium and measuring the amount of EFV. Briefly, the pericardial contour was automatically delineated by a U-net framework, details of which are described in a previous report from our group (12). The segmentation results were further checked and modified by two experienced cardiac imaging physicians (J.H. and M.Q.) blinded to both the study plan and the clinical data. Modifications, including manual small scale enlargment or shrinking of the imaging annotation range, were made to ensure that the segmentation results of the pericardial boundary matched exactly with its anatomical structure. The upper boundary of the pericardium was taken as the bifurcation of the pulmonary trunk and the lower limit was the apex of the heart. Epicardial fat was defined as all voxels with attenuation values between $-190 \mathrm{HU}$ and $-30 \mathrm{HU}$. Thus all voxels having attenuation values within this range and lying within the pericardium were thresholded accordingly and 
used for EFV level quantification (Figure 2). The value of EFV was normalized to body surface area (BSA) where the BSA was calculated with the Mosteller equation (13). Epicardial fat attenuation index (FAI) was defined as the average attenuation of adipose tissue within the pre-specified attenuation window of -190 $\mathrm{HU}$ to $-30 \mathrm{HU}$.

For reproducibility assessment, images from 30 patients with three-vessel CAD were randomly selected. The pericardial contour was automatically delineated using the U-net framework mentioned above. Two radiologists (J.H. and M.Q.) reviewed and modified the automatic pericardial segmentation to ensure a good match with the pericardial anatomy. After four weeks, one of the radiologists (J.H.) reviewed and modified the pericardial segmentation output again. The value of EFV and epicardial FAI derived from the semi-automatic segmentation results of the pericardium was employed for reproducibility assessment using intraclass correlation coefficient analysis.

\section{Analysis of coronary atherosclerosis severity}

Coronary atherosclerosis severity was quantified by the number of coronary arteries having $\geq 50 \%$ stenosis on ICA $(11,14)$. Stenoses in the left anterior descending, left circumflex, and right coronary artery were each scored as a single vessel lesion and stenoses in the left main coronary artery were more strongly weighted by being scored as two vessel lesions. Stenoses in the remaining secondary branches of the coronary arteries (such as the diagonal artery, obtuse marginal artery, posterolateral artery, and posterior descending artery) with $\geq 50 \%$ stenosis were each scored as 0.5 of a lesion.

The three-vessel CAD patients were subdivided into three groups according to coronary atherosclerosis severity: mild (score $=3$ vessels, $n=85$ ), moderate ( 3.5 vessels $\leq$ score $<4$ vessels, $n=82$ ), and severe (4 vessels $\leq$ score $\leq 7$ vessels, $n=85$ ). Patients with more than three vessel lesions were divided into two subgroups based on the median score (4 lesions) of coronary atherosclerosis severity.

\section{Statistical analysis}

Continuous variables were expressed as mean \pm standard deviation or medians and interquartile range. Categorical variables were expressed as number and percentage. The Kolmogorov-Smirnov test was employed to test for the normal distribution of continuous data. Comparisons of continuous variables were conducted using the independent $t$-test and one-way analysis of variance (ANOVA), with the least significant difference (LSD) method for multiple comparisons. Comparisons of categorical variables were performed with the Chi-square test. The relation of EFV level to mean epicardial FAI, LV function, and BMI were assessed with Pearson's correlation analysis. Multivariable logistic regression analysis was used for co-variables that had a significant effect in the univariable logistic regression analysis, aiming to identify the independent factors associated with a change of EFV level. Interobserver and intraobserver agreement for EFV level and epicardial FAI quantification were assessed by evaluating the intraclass correlation coefficient (ICC). Statistical analysis was performed with SPSS software (SPSS statistics, version 26.0, IBM Corp.). Two-sided testing was used and $P<0.05$ was considered to be statistically significant. 


\section{Results}

\section{Study population characteristics}

A total of 252 consecutive three-vessel CAD patients and 252 control group participants were included in this retrospective study. Detailed baseline demographic and clinical data are listed in Table 1. Compared with lesion-free controls, three-vessel CAD patients had significantly higher EFV level (EFV: $120 \pm 42$ vs 89 $\pm 32 \mathrm{ml}$, EFV/BSA: $65 \pm 22$ vs $\left.48 \pm 19 \mathrm{~mL} / \mathrm{m}^{2} ; P<0.001\right)$ and higher mean epicardial FAl $(-81 \pm 5$ vs $-84 \pm$ $9 \mathrm{HU}, P<0.001)$.

According to the median EFV level $\left(118 \mathrm{~cm}^{3}\right)$, three-vessel CAD patients were categorized into low $(<118$ $\mathrm{ml}, \mathrm{n}=125)$ and high EFV level subgroups ( $\geq 118 \mathrm{ml}, \mathrm{n}=127$ ). Compared with the low EFV subgroup, patients with high EFV had significantly higher BMI (26 \pm 3 vs $\left.24 \pm 3 \mathrm{~kg} / \mathrm{m}^{2}, P<0.001\right)$ and larger LV diameter (49 \pm 4.0 vs $48 \pm 4.5 \mathrm{~mm}, P=0.023$ ) (Table 1 ).

\section{Relation of EFV level to risk factors and LV function}

Subgroup analysis of EFV level, separated into two groups by median BMI $\left(25 \mathrm{~kg} / \mathrm{m}^{2}\right)$, revealed a significantly higher EFV in overweight patients than in those with normal body weight (EFV: $134 \pm 41$ vs $105 \pm 39 \mathrm{ml}, t=5.786, P<0.001$; EFV/BSA: $\left.70 \pm 21 \mathrm{vs} 60 \pm 21 \mathrm{~mL} / \mathrm{m}^{2}, t=3.603, P<0.001\right)$. Hypertensive patients had a significantly higher EFV (123 \pm 42 vs $110 \pm 42 \mathrm{ml}, t=2.229, P=0.027$; EFV/BSA: $67 \pm 21$ vs $\left.60 \pm 22 \mathrm{~mL} / \mathrm{m}^{2}, t=2.322, P=0.021\right)$. In comparison to patients who had normal LV diastolic function $(E / A>1, n=203)$, those with LV diastolic dysfunction $(E / A<1, n=49)$ had a lower EF and lower EFV relative to BSA, although only the latter was statistically significant (EFV: $110 \pm 43$ vs $122 \pm 42 \mathrm{ml}, t=$ -1.868, $P=0.063$; EFV/BSA: $60 \pm 22$ vs $\left.67 \pm 21 \mathrm{~mL} / \mathrm{m}^{2}, t=-1.988, P=0.048\right)$. However, there were no significant differences of EFV level between the two subgroups in the variables related to gender, smoking, dyslipidemia, diabetes mellitus, or family history of CAD $(P>0.05)$.

Pearson correlation analysis showed that, for all CAD subjects, EFV was positively and significantly correlated with BMI $(r=0.407, P<0.001)$ and negatively, with mean epicardial FAI $(r=-0.709, P<0.001)$.

\section{Relation of EFV, FAI, and LV function to the severity of coronary atherosclerosis}

Table 2 and Figures $3 \mathrm{a}$ and $3 \mathrm{~b}$ show that increasing stenosis severity was significantly associated with reduced EFV. There was a statistically significant inverse relationship between EFV and severity of coronary atherosclerosis ( $126 \pm 45$ vs $124 \pm 45$ vs $110 \pm 34 \mathrm{ml}, \mathrm{F}=3.818, P=0.023$ ). Post hoc tests using the LSD method showed that the differences between the mild and severe coronary atherosclerosis subgroups were statistically significant $(t=16.212, P=0.012)$, as well as for the comparison between the moderate and severe subgroups $(t=14.301, P=0.028)$. When normalized to BSA, the relationship was maintained and remained significant although the effect was weaker (69 \pm 23 vs $67 \pm 23$ vs $60 \pm 17$ $\left.\mathrm{mL} / \mathrm{m}^{2}, P=0.036\right)$. 
Table 2

Comparison of EFV level, FAl, and LV function in three-vessel CAD

\begin{tabular}{|c|c|c|c|c|}
\hline \multirow[t]{2}{*}{ Variables } & \multicolumn{3}{|c|}{ Score of coronary atherosclerosis severity ${ }^{*}$} & \multirow[t]{2}{*}{$P$-value } \\
\hline & Mild & Moderate & Severe & \\
\hline All patients ( $n=252)$ & $85(34)$ & $82(32)$ & $85(34)$ & \\
\hline $\mathrm{EFV}(\mathrm{ml})$ & $126 \pm 45$ & $124 \pm 45$ & $110 \pm 34$ & 0.045 \\
\hline $\mathrm{EFV} / \mathrm{BSA}\left(\mathrm{mL} / \mathrm{m}^{2}\right)$ & $69 \pm 23$ & $67 \pm 23$ & $60 \pm 17$ & 0.036 \\
\hline Epicardial FAI (HU) & $-81 \pm 5.5$ & $-77 \pm 4.5$ & $-73 \pm 4.3$ & $<0.001$ \\
\hline LV diameter (mm) & $48 \pm 4.3$ & $48 \pm 4.5$ & $48 \pm 4.0$ & 0.967 \\
\hline LVEF (\%) & $60 \pm 6.3$ & $60 \pm 5.6$ & $60 \pm 6.2$ & 0.952 \\
\hline $\mathrm{E} / \mathrm{A}$ & $1.3 \pm 0.4$ & $1.3 \pm 0.3$ & $1.3 \pm 0.4$ & 0.931 \\
\hline \multicolumn{5}{|l|}{ Patients stratified by BMI\# } \\
\hline $\mathrm{BMI}<25 \mathrm{~kg} / \mathrm{m}^{2}(\mathrm{n}=124)$ & $41(33)$ & $37(30)$ & $46(37)$ & \\
\hline $\mathrm{EFV}(\mathrm{ml})$ & $107 \pm 43$ & $107 \pm 42$ & $103 \pm 31$ & 0.86 \\
\hline $\mathrm{EFV} / \mathrm{BSA}\left(\mathrm{mL} / \mathrm{m}^{2}\right)$ & $62 \pm 24$ & $62 \pm 24$ & $58 \pm 17$ & 0.857 \\
\hline Epicardial FAI (HU) & $-79 \pm 6.6$ & $-77 \pm 4.7$ & $-72 \pm 3.9$ & $<0.001$ \\
\hline LV diameter (mm) & $48 \pm 4.3$ & $47 \pm 4.3$ & $48 \pm 4.0$ & 0.448 \\
\hline LVEF (\%) & $60 \pm 5.8$ & $61 \pm 6.1$ & $60 \pm 6.2$ & 0.788 \\
\hline $\mathrm{E} / \mathrm{A}$ & $1.2 \pm 0.5$ & $1.3 \pm 0.3$ & $1.2 \pm 0.3$ & 0.945 \\
\hline $\mathrm{BMI} \geq 25 \mathrm{~kg} / \mathrm{m}^{2}(\mathrm{n}=128)$ & $44(34)$ & $45(35)$ & $39(31)$ & \\
\hline $\mathrm{EFV}(\mathrm{ml})$ & $144 \pm 40$ & $139 \pm 43$ & $118 \pm 35$ & 0.01 \\
\hline $\mathrm{EFV} / \mathrm{BSA}\left(\mathrm{mL} / \mathrm{m}^{2}\right)$ & $75 \pm 21$ & $72 \pm 22$ & $62 \pm 17$ & 0.013 \\
\hline Epicardial FAI (HU) & $-82 \pm 4.0$ & $-78 \pm 4.4$ & $-74 \pm 4.5$ & $<0.001$ \\
\hline LV diameter (mm) & $49 \pm 4.2$ & $49 \pm 4.4$ & $49 \pm 4.2$ & 0.802 \\
\hline
\end{tabular}

\footnotetext{
* Patients were subdivided into groups according to their coronary atherosclerosis severity: mild ( score $=3$ vessels), moderate $(3.5 \leq$ score $<4$ vessels $)$, and severe $(4 \leq$ score $\leq 7$ vessels).

\# Patients were categorized by median BMI $\left(25 \mathrm{~kg} / \mathrm{m}^{2}\right)$.

EFV, epicardial fat volume; FAl, fat attenuation index; LV, left ventricular; CAD, coronary artery disease; $\mathrm{BSA}$, body surface area; EF, ejection fraction; $\mathrm{BMI}$, body mass index.
} 


\begin{tabular}{|c|c|c|c|c|}
\hline \multirow[t]{2}{*}{ Variables } & \multicolumn{3}{|c|}{ Score of coronary atherosclerosis severity ${ }^{*}$} & \multirow[t]{2}{*}{$P$-value } \\
\hline & Mild & Moderate & Severe & \\
\hline LVEF (\%) & $60 \pm 6.7$ & $60 \pm 5.2$ & $59 \pm 6.2$ & 0.725 \\
\hline $\mathrm{E} / \mathrm{A}$ & $1.3 \pm 0.4$ & $1.3 \pm 0.3$ & $1.3 \pm 0.4$ & 0.825 \\
\hline \multicolumn{5}{|c|}{$\begin{array}{l}\text { *Patients were subdivided into groups according to their coronary atherosclerosis severity: mild } \\
\text { (score }=3 \text { vessels), moderate ( } 3.5 \leq \text { score }<4 \text { vessels), and severe ( } 4 \leq \text { score } \leq 7 \text { vessels). }\end{array}$} \\
\hline \multicolumn{5}{|c|}{ \# Patients were categorized by median BMI $\left(25 \mathrm{~kg} / \mathrm{m}^{2}\right)$. } \\
\hline \multicolumn{5}{|c|}{$\begin{array}{l}\text { EFV, epicardial fat volume; FAl, fat attenuation index; LV, left ventricular; CAD, coronary artery disease } \\
\text { BSA, body surface area; EF, ejection fraction; BMI, body mass index. }\end{array}$} \\
\hline
\end{tabular}

When grouped according to the median BMI $\left(25 \mathrm{~kg} / \mathrm{m}^{2}\right)$, there was, similarly, a progressive decline in EFV level from the mild, moderate to severe coronary atherosclerosis subgroups in the higher BMI group (EFV: $144 \pm 40$ vs $139 \pm 43$ vs $118 \pm 35 \mathrm{ml}, P=0.01 ;$ EFV/BSA: $75 \pm 21$ vs $72 \pm 22$ vs $62 \pm 17 \mathrm{~mL} / \mathrm{m}^{2}, P=0.013$ ) (Table 2; Figure 3c, 3d). Post hoc tests using the LSD method showed that, in comparison to the severe atherosclerosis subgroup, both the mild (EFV: $t=25.678, P=0.004$; EFV/BSA: $t=12.670, P=0.005$ ) and the moderate atherosclerosis subgroups (EFV: $t=20.480, P=0.020$; EFV/BSA: $t=10.164, P=0.023$ ) had significantly higher EFVs. However, no significant relationship between EFV level and atheroslcerotic severity was seen in patients with BMls below the median value Additionally, there was a significant positive association between the severity of coronary atherosclerosis and the mean attenuation due to epicardial fat (FAl) $(-81 \pm 5.5$ vs $-77 \pm 4.5$ vs $-73 \pm 4.3 \mathrm{HU}, P<0.001)$ for the mild, moderate and severe atherosclerosis levels, respectively. However, there were no significant differences between the mild, moderate, and severe atherosclerosis subgroups in the variables related to LV function, namely LV diameter, LVEF, or E/A $(P>0.05)$.

\section{Analysis of factors related to the change of EFV level}

Univariate and multivariable logistic regression analysis showed that BMI (OR: 3.40,95\% Cl: 2.00-5.78, $P$ $<0.001)$ and coronary atherosclerosis severity (OR: $0.49,95 \% \mathrm{Cl}: 0.26-0.93, P=0.03)$ were independently associated with the change of EFV level in all patients (Table 3 ). 
Table 3

Factors associated with EFV level in three-vessel CAD

\begin{tabular}{|c|c|c|c|c|}
\hline \multirow[t]{2}{*}{ Variables } & \multicolumn{2}{|c|}{ Univariable analysis } & \multicolumn{2}{|c|}{$\begin{array}{l}\text { Multivariable analysis } \\
\text { (univariable } P<0.05 \text { ) }\end{array}$} \\
\hline & OR (95\% Cl) & $P$-value & OR (95\% Cl) & $P$-value \\
\hline Age & $\begin{array}{l}1.02(0.99 ; \\
1.06)\end{array}$ & 0.163 & & \\
\hline Gender & $\begin{array}{l}0.70(0.38 \\
1.19)\end{array}$ & 0.168 & & \\
\hline Smoking & $\begin{array}{l}1.21(0.74 ; \\
1.98)\end{array}$ & 0.452 & & \\
\hline Hypertension & $\begin{array}{l}1.45(0.81 \\
2.60)\end{array}$ & 0.211 & & \\
\hline Dyslipidemia & $\begin{array}{l}1.40(0.75 \\
2.63)\end{array}$ & 0.294 & & \\
\hline Diabetes & $\begin{array}{l}1.26(0.76 \\
2.07)\end{array}$ & 0.366 & & \\
\hline $\mathrm{BMI}^{*}$ & $\begin{array}{l}3.60(2.14 \\
6.05)\end{array}$ & $<0.001$ & $\begin{array}{l}3.40(2.00 \\
5.78)\end{array}$ & $<0.001$ \\
\hline CAD family history & $\begin{array}{l}0.66(0.30 \\
1.45)\end{array}$ & 0.304 & & \\
\hline LV diameter & $\begin{array}{l}1.07(1.00 \\
1.14)\end{array}$ & 0.025 & $\begin{array}{l}1.06(0.99 \\
1.13)\end{array}$ & 0.104 \\
\hline LVEF & $\begin{array}{l}1.00(0.96 \\
1.05)\end{array}$ & 0.91 & & \\
\hline $\mathrm{E} / \mathrm{A}$ & $\begin{array}{l}1.94(0.98 \\
3.84)\end{array}$ & 0.058 & & \\
\hline $\begin{array}{l}\text { Score of coronary atherosclerosis } \\
\text { severity\# }\end{array}$ & $\begin{array}{l}0.49(0.27 \\
0.90)\end{array}$ & 0.022 & $\begin{array}{l}0.49(0.26 \\
0.93)\end{array}$ & 0.03 \\
\hline CCC status & $\begin{array}{l}0.91(0.53 \\
1.55)\end{array}$ & 0.72 & & \\
\hline
\end{tabular}

* Patients were divided into lower $\left(<25 \mathrm{~kg} / \mathrm{m}^{2}\right)$ and higher $\left(\geq 25 \mathrm{~kg} / \mathrm{m}^{2}\right)$ BMl groups.

\# Patients were divided into groups according to their coronary atherosclerosis severity: mild (score = 3 vessels), moderate ( $3.5 \leq$ score $<4$ vessels), and severe ( $4 \leq$ score $\leq 7$ vessels).

EFV, epicardial fat volume; CAD, coronary artery disease; OR, odds ratio; $\mathrm{BMI}$, body mass index; LV, left ventricular; EF, ejection fraction; CCC, coronary collateral circulation. 


\begin{tabular}{|llll|}
\hline Variables & \multicolumn{2}{l}{ Univariable analysis } & \multicolumn{2}{l|}{$\begin{array}{l}\text { Multivariable analysis } \\
\text { (univariable } P<0.05)\end{array}$} \\
\cline { 2 - 4 } & OR $(95 \% \mathrm{Cl})$ & $P$-value & OR $(95 \% \mathrm{Cl}) \quad P$-value \\
\hline SYNTAX score & $\begin{array}{l}0.99(0.97 ; \\
1.02)\end{array}$ & 0.57 & \\
\hline
\end{tabular}

* Patients were divided into lower $\left(<25 \mathrm{~kg} / \mathrm{m}^{2}\right)$ and higher $\left(\geq 25 \mathrm{~kg} / \mathrm{m}^{2}\right)$ BMI groups.

\# Patients were divided into groups according to their coronary atherosclerosis severity: mild (score = 3 vessels), moderate ( $3.5 \leq$ score $<4$ vessels), and severe ( $4 \leq$ score $\leq 7$ vessels).

EFV, epicardial fat volume; CAD, coronary artery disease; OR, odds ratio; $\mathrm{BMI}$, body mass index; LV, left ventricular; EF, ejection fraction; CCC, coronary collateral circulation.

\section{Reproducibility assessment}

Intraclass correlation coefficient analysis revealed excellent interobserver and intraobserver agreement for EFV level and epicardial FAI measurement. Interobserver analysis showed 0.97, 0.95 agreement for EFV level and epicardial FAI, respectively. Intraobserver analysis showed 0.99, 0.97 agreement for EFV level and epicardial FAl, respectively.

\section{Discussion}

The results show that three-vessel CAD patients had significantly higher EFV levels than those of the normal controls. Furthermore, stratifying the severity of atherosclerosis into mild, moderate and severe levels showed that there was an inverse relationship between EFV level assessed with CCTA and coronary atherosclerosis severity in three-vessel CAD.

Many clinical studies have demonstrated that EFV level on CCTA is related to the presence and severity of coronary atherosclerosis. For instance, in the Framingham Heart Study, measurements in more than 3000 individuals showed that increased EFV was associated with the presence of CAD (8). EFV level was also related to coronary atherosclerosis severity, coronary artery calcium score, and the characteristics of unstable atherosclerotic plaques (8-10). Here, we found that three-vessel CAD patients had significantly higher EFVs than those of the normal controls, which is consistent with the previous studies $(8-10)$.

Interestingly, we observed a progressive decline in EFV level with increasing coronary atherosclerotic severity in all three-vessel CAD patients, although it was statistically significant only those with $\mathrm{BMI} \geq$ $25 \mathrm{~kg} / \mathrm{m}^{2}$. Gorter et al. (11) also reported that patients with more severe coronary atherosclerosis tended to have lower EFVs although their study sample contained only 128 subjects. We believe there are two plausible explanations for this inverse association between disease severity and EFV. One is that fewer numbers of epicardial adipocytes and an increased number of small and immature epicardial perivascular preadipocytes in patients with severe coronary atherosclerosis would imply a reduced 
absolute EFV level. In the three-vessel CAD patients with chronic coronary vascular inflammation and severe coronary atherosclerosis, chronic hypoxia and an unfavorable hemodynamic environment would affect the regulatory component of the epicardial fat proteasome, which would accelerate the apoptosis of epicardial adipocytes. This hypothesis is supported by evidence that several genes involved in cellular function are downregulated in the epicardial adipocytes of advanced CAD (15). Furthermore, recent evidence has revealed a bidirectional signaling between epicardial adipose tissue and vascular inflammatory cells $(16,17)$. Epicardial adipocytes could, therefore, modulate structural changes and inflammation in the vascular wall via paracrine mechanisms and vascular wall-derived inflammatory factors could block the differentiation of epicardial adipocytes. In three-vessel CAD patients, the remodelling of adipocytes due to vessel inflammation was more obvious than that in patients with mild or moderate CAD. Therefore, the end result could be large proportion of small and immature epicardial perivascular pre-adipocytes around vessels, thus leading to a reduction of EFV. The second explanation for reduced EFV in those with severe CAD is related to changes in the composition of epicardial adipocytes which could increase the degree to which they attenuate incident $x$-rays. If this were to happen, fewer voxels would fall within the thresholded range and, this would lead to an apparent reduction in EFV. This effect is likely to be seen in CAD patients who have had long-standing and complex coronary atherosclerosis, which is associated with irreversible changes in epicardial perivascular adipocyte composition, such as inflammatory infiltration, microvascular remodeling and extracellular fibrosis $(18,19)$. Furthermore, according to the bidirectional interaction hypothesis mentioned above $(16$, 17), epicardial fat preadipocytes tend to be of smaller size and contain less intracellular lipid than that of mature epicardial adipocytes. The loss of balance between lipid and water content in epicardial perivascular preadipocytes would result in a rise of epicardial FAI. The change of epicardial fat composition in three-vessel CAD patients with more severe coronary atherosclerosis leads to an increase of epicardial FAl, which, in turn, leads to a significant reduction of EFV level when measuring CCTA images using threshold-based methods. This hypothesis is consistent with the results reported here in which three-vessel CAD patients with severe coronary atherosclerosis had significantly higher epicardial FAl. These observations are also consistent with previous studies which have reported increased epicardial FAI in patients with advanced CAD or acute coronary syndrome $(20,21)$.

Additionally, we observed a significantly higher EFV in hypertensive subjects and those in the higher BMI group, again in line with previous studies $(22,23)$. We also found that in patients with LV diastolic dysfunction there was a tendency towards lower EFV, although this was not statistically significant. A possible explanation is that epicardial fat is associated with both visible epicardial coronary atherosclerosis and coronary microvascular dysfunction, both of which would lead to impaired myocardial perfusion and contractile function (24).

There are several limitations to the study. First, it was a retrospective single-center study and the sample size was relatively small. Second, even though we adopted a commonly used method for classifying the severity of coronary atherosclerosis $(11,14)$, it did not account for the stability of the atherosclerotic plaque. Third, it has been reported that statin therapy is associated with a reduction in epicardial fat accumulation, especially when given in high doses (atorvastatin $80 \mathrm{mg} /$ day) (25). However, in this study, 
all the CAD patients were given moderate doses (atorvastatin 10-20 mg/day), this being based on expert recommendation for Chinese subjects (26). Whether a significant reduction of EFV in three-vessel CAD patients with severe coronary atherosclerosis is associated with moderate statin therapy needs further clinical studies to confirm.

\section{Conclusions}

Patients with three-vessel CAD have significantly higher EFV level than age-, gender- and BMI-matched normal controls. Furthermore, our study results show that there is an potential inverse relationship between EFV level and coronary atherosclerosis severity in three-vessel CAD. Therefore, the value of clinical applications of the current study may be that a fall in EFV level on CCTA images during follow-up of patients with three-vessel CAD is a potential imaging biomarker of disease progression, which will contribute to the clinical management of three-vessel CAD. However, future larger-scale studies are required for the validation of our findings.

\section{List Of Abbreviations}

BMl: Body mass index

BSA: Body surface area

CAD: Coronary artery disease

CCTA: Coronary computed tomography angiography

EF: Ejection fraction

EFV: Epicardial fat volume

FAl: Fat attenuation index

HU: Hounsfield units

ICA: Invasive coronary angiography

LV: Left ventricular

\section{Declarations}

\section{Ethics approval and consent to participate}

The study protocol was approved by the ethics committee of the General Hospital of Northern Theater Command (Y [2021] 012) and the study complied with the Declaration of Helsinki. Informed consent was waived by the committee because of the retrospective nature of this study. 


\section{Consent for publication}

Not applicable.

\section{Availability of data and materials}

The datasets used and/or analysed during the current study are available from the corresponding author on reasonable request.

\section{Competing interests}

The authors declare that they have no competing interests.

\section{Funding}

This study is supported by the National Natural Science Foundation of China (61773110), the Key Research and Development Program of Liaoning Province, China (2018225024). The funders play an important role in study design, data analysis, and preparation of the manuscript.

\section{Authors' contributions}

Y.S. collected and analyzed the study population data, and was a major contributor in writing the manuscript. X.G.L. contributed to the development of deep learning model used in this study and the interpretation of data. K.X. contributed to the design of this study and the analysis of data. J.H., and M.Q. contributed to the collection and interpretation of data. H.R.Y., R.R.Z., L.B.Z., L.S.X., and S.E.G. contributed to the development of deep learning model. B.Q.Y. contributed to the conception of the work and analysis of data, and was a major contributor in revising the manuscript. All authors read and approved the final manuscript.

\section{Acknowledgements}

Not applicable.

\section{References}

1. Serruys PW, Kogame N, Katagiri Y, Modolo R, Onuma Y. Clinical outcomes of state-of-the-art percutaneous coronary revascularisation in patients with three-vessel disease: two-year follow-up of the SYNTAX II study. Eurolntervention. 2019;15: e244-52.

2. Park SJ, Ahn JM, Kim YH, Park DW, Yun SC, Lee JY, et al. Trial of everolimus-eluting stents or bypass surgery for coronary disease. N Engl J Med. 2015;372:1204-12.

3. Makikallio T, Holm NR, Lindsay M, Spence MS, Erglis PA, Menown IBA, et al. Percutaneous coronary angioplasty versus coronary artery bypass grafting in treatment of unprotected left main stenosis (NOBLE): a prospective, randomized, open-label, non-inferiority trial. Lancet. 2016;388:2743-52. 
4. Hueb WA, Lopes N, Gersh BJ, Soares PR, Ribeiro EE, Pereira AC, et al. Ten-year follow-up survival of the medicine, angioplasty, or surgery study (MASS II): A randomized controlled clinical trial of 3 therapeutic strategies for multivessel coronary artery disease. Circulation. 2010;122:949-57.

5. Maron DJ, Hochman JS, Reynolds HR, Bangalore S, O'Brien SM, Boden WE, et al. Initial invasive or conservative strategy for stable coronary disease. N Engl J Med. 2020;382:1395-407.

6. Mazurek T, Opolski G. Pericoronary adipose tissue: A novel therapeutic target in obesity-related coronary atherosclerosis. J Am Coll Nutr. 2015;34:244-54.

7. Lu MT, Park J, Ghemigian K, Mayrhofer T, Puchner SB, Liu T, et al. Epicardial and paracardial adipose tissue volume and attenuation - Association with high-risk coronary plaque on computed tomographic angiography in the ROMICAT II trial. Atherosclerosis. 2016;251:47-54.

8. Thanassoulis G, Massaro JM, Hoffmann U, Mahabadi AA, Vasan RS, O'Donnell CJ, et al. Prevalence, distribution, and risk factor correlates of high pericardial and intrathoracic fat depots in the Framingham heart study. Circ Cardiovasc Imaging. 2010;3:559-66.

9. Yu WJ, Liu B, Zhang FF, Wang JF, Shao XL, Yang XY, et al. Association of epicardial fat volume with increased risk of obstructive coronary artery disease in Chinese patients with suspected coronary artery disease. J Am Heart Assoc. 2021;10: e018080.

10. Mancio J, Azevedo D, Saraiva F, Azevedo Al, Pires-Morais G, Leite-Moreira A, et al. Epicardial adipose tissue volume assessed by computed tomography and coronary artery disease: a systematic review and meta-analysis. Eur Heart J Cardiovasc Imaging. 2018;19:490-7.

11. Gorter PM, Vos AMD, Graaf YVD, Stella PR, Doevendans PA, Meijs MFL, et al. Relation of epicardial and pericoronary fat to coronary atherosclerosis and coronary artery calcium in patients undergoing coronary angiography. Am J Cardiol. 2008;102:380-5.

12. Li XG, Sun Y, Xu LS, Greenwald SE, Zhang LB, Zhang RR, et al. Automatic quantification of epicardial adipose tissue volume. Med Phys. 2021;48:4279-90.

13. Mosteller RD. Simplified calculation of body-surface area. N Engl J Med. 1987;317:1098.

14. Scanlon PJ, Faxon DP, Audet AM, Carabello B, Dehmer GJ, Eagle KA, et al. ACC/AHA guidelines for coronary angiography. A report of the American College of Cardiology/American Heart Association Task Force on practice guidelines (Committee on Coronary Angiography). Developed in collaboration with the Society for Cardiac Angiography and Interventions. J Am Coll Cardiol. 1999;33:1756-824.

15. Camarena V, Sant D, Mohseni M, Salerno T, Zaleski ML, Wang G, et al. Novel atherogenic pathways from the differential transcriptome analysis of diabetic epicardial adipose tissue. Nutr Metab Cardiovasc Dis. 2017;27:739-50.

16. Margaritis M, Antonopoulos AS, Digby J, Lee R, Reilly S, Coutinho P, et al. Interaction between vascular wall and perivascular adipose tissue reveal novel roles for adiponectin in the regulation of endothelial nitric oxide synthase function in human vessels. Circulation. 2013;127:2209-21.

17. Antonopoulos AS, Sanna F, Sabharwal N, Thomas S, Oikonomou EK, Herdman L, et al. Detecting human coronary inflammation by imaging perivascular fat. Sci Transl Med. 2017;9: eaal2658. 
18. Oikonomou EK, Antoniades C. The role of adipose tissue in cardiovascular health and disease. Nat Rev Cardiol. 2019;16:83-99.

19. Mancio J, Oikonomou EK, Antoniades C. Perivascular adipose tissue and coronary atherosclerosis. Heart. 2018;104:1654-62.

20. Liu ZH, Wang SJ, Wang YQ, Zhou NB, Shu J, Stamm C, et al. Association of epicardial adipose tissue attenuation with coronary atherosclerosis in patients with a high risk of coronary artery disease. Atherosclerosis 2019;284:230-36.

21. Hedgire S, Baliyan V, Zucker EJ, Bittner DO, Staziaki PV, Takx RAP, et al. Perivascular epicardial fat stranding at coronary $\mathrm{CT}$ angiography: A marker of acute plaque rupture and spontaneous coronary artery dissection. Radiology. 2018;287:808-15.

22. Yorgun $\mathrm{H}$, Canpolat $\mathrm{U}$, Hazirolan $\mathrm{T}$, Ates $\mathrm{AH}$, Sunman $\mathrm{H}$, Dural $\mathrm{M}$, et al. Increased epicardial fat tissue is a marker of metabolic syndrome in adult patients. Int $\mathrm{J}$ Cardiol. 2013;165:308-13.

23. Gorter PM, van Lindert AS, de Vos AM, Meijs MFL, van der Graaf Y, Doevendans PA, et al. Quantification of epicardial and peri-coronary fat using cardiac computed tomography; reproducibility and relation with obesity and metabolic syndrome in patients suspected of coronary artery disease. Atherosclerosis. 2008;197:896-903.

24. Cavalcante JL, Tamarappoo BK, Hachamovitch R, Kwon DH, Alraies MC, Halliburton S, et al. Association of epicardial fat, hypertension, subclinical coronary artery disease, and metabolic syndrome with left ventricular diastolic dysfunction. Am J Cardiol. 2012;110:1793-8.

25. Alexopoulos N, Melek BH, Arepalli CD, Hartlage GR, Chen Z, Kim S, et al. Effect of intensive versus moderate lipid-lowering therapy on epicardial adipose tissue in hyperlipidemic post-menopausal women: a substudy of the BELLES trial (Beyond Endorsed Lipid Lowering with EBT Scanning). J Am Coll Cardiol. 2013;61:1956-61.

26. Zhao SP, Yu BL, Peng DQ, Huo Y. The effect of moderate-dose versus double-dose statins on patients with acute coronary syndrome in China: Results of the CHILLAS trial. Atherosclerosis. 2014;233:70712.

\section{Figures}


$\mathrm{n}=1608$, CT-based diagnosed consecutive patients with three-vessel CAD between January 2018 and December 2019

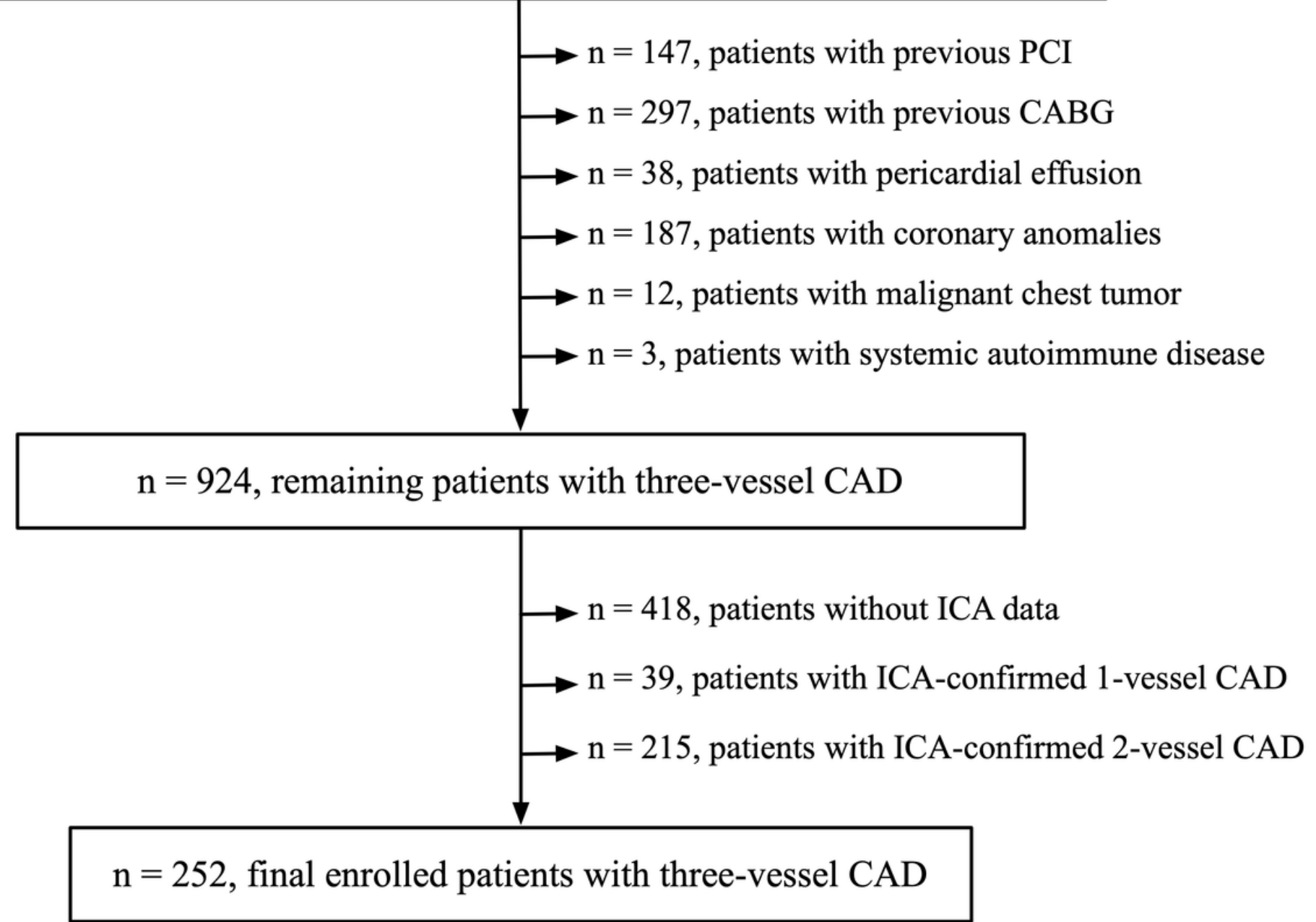

Figure 1

\section{Study flowchart}

$\mathrm{CT}$, computed tomography; $\mathrm{CAD}$, coronary artery disease; $\mathrm{PCl}$, percutaneous coronary intervention; $\mathrm{CABD}$, coronary artery bypass grafting; ICA, invasive coronary angiography. 


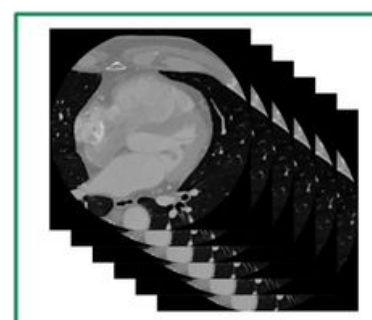

Coronary CTA Images

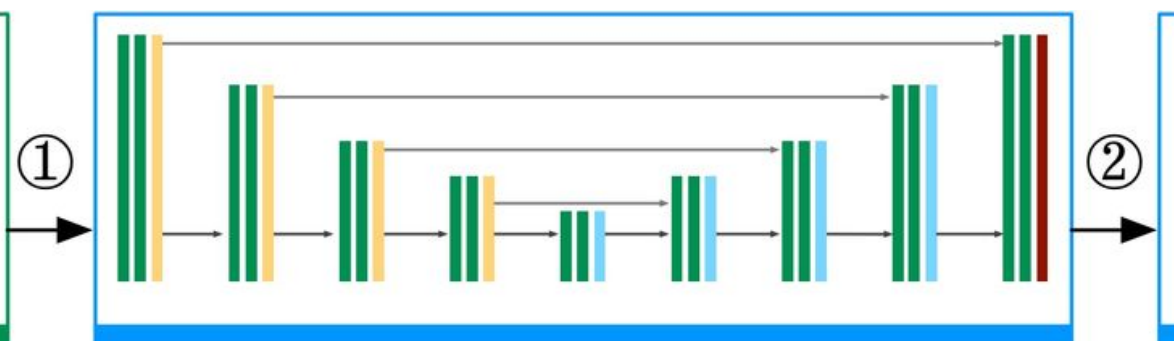

U-Net Framework

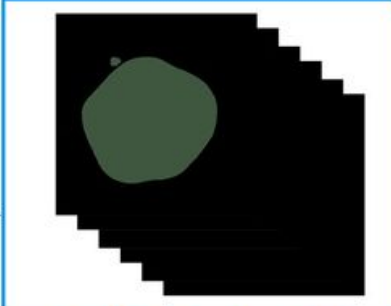

Initial Pericardial Segmentation

Checked and Modified by Radiologist

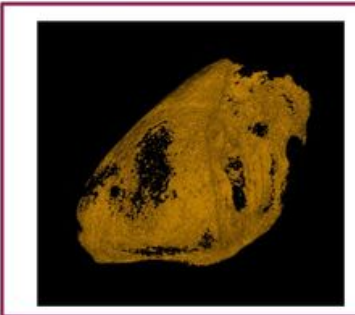

EFV Level
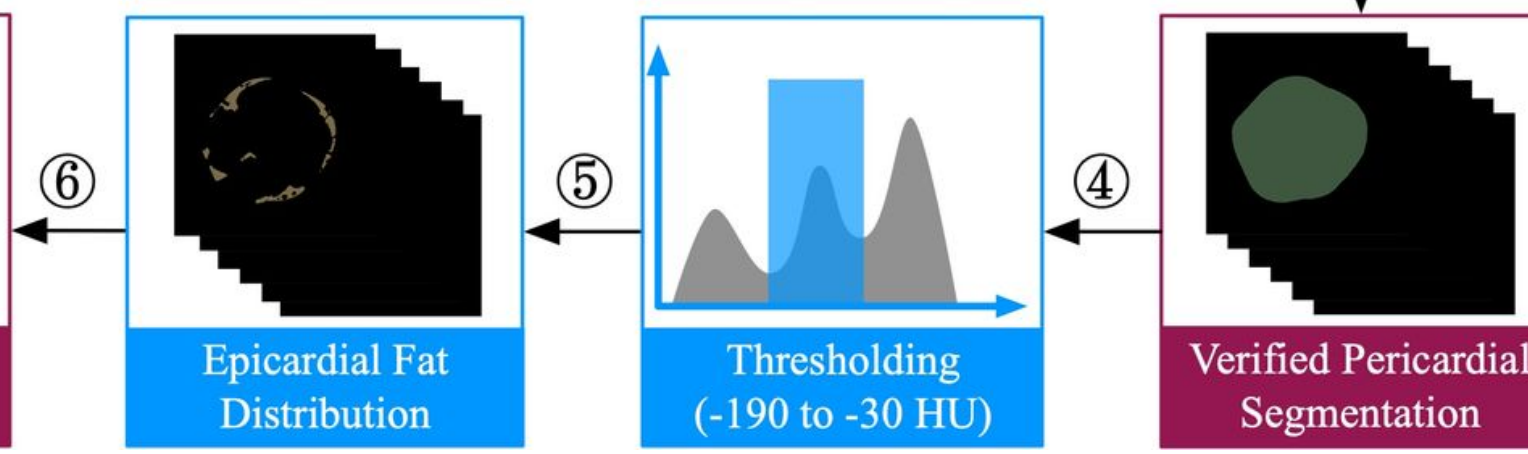

Verified Pericardial Segmentation

Figure 2

\section{Semi-automatic quantification of EFV level from CCTA images}

Axial CCTA images at $75 \%$ of the R-R interval were processed for pericardial segmentation using the U-Net framework. The initial results were checked and modified by two radiologists and the epicardial fat was identified as those voxels lying between upper and lower threshold values of -30 and $-190 \mathrm{HU}$.

EFV, epicardial fat volume; CCTA, coronary computed tomography angiography. 

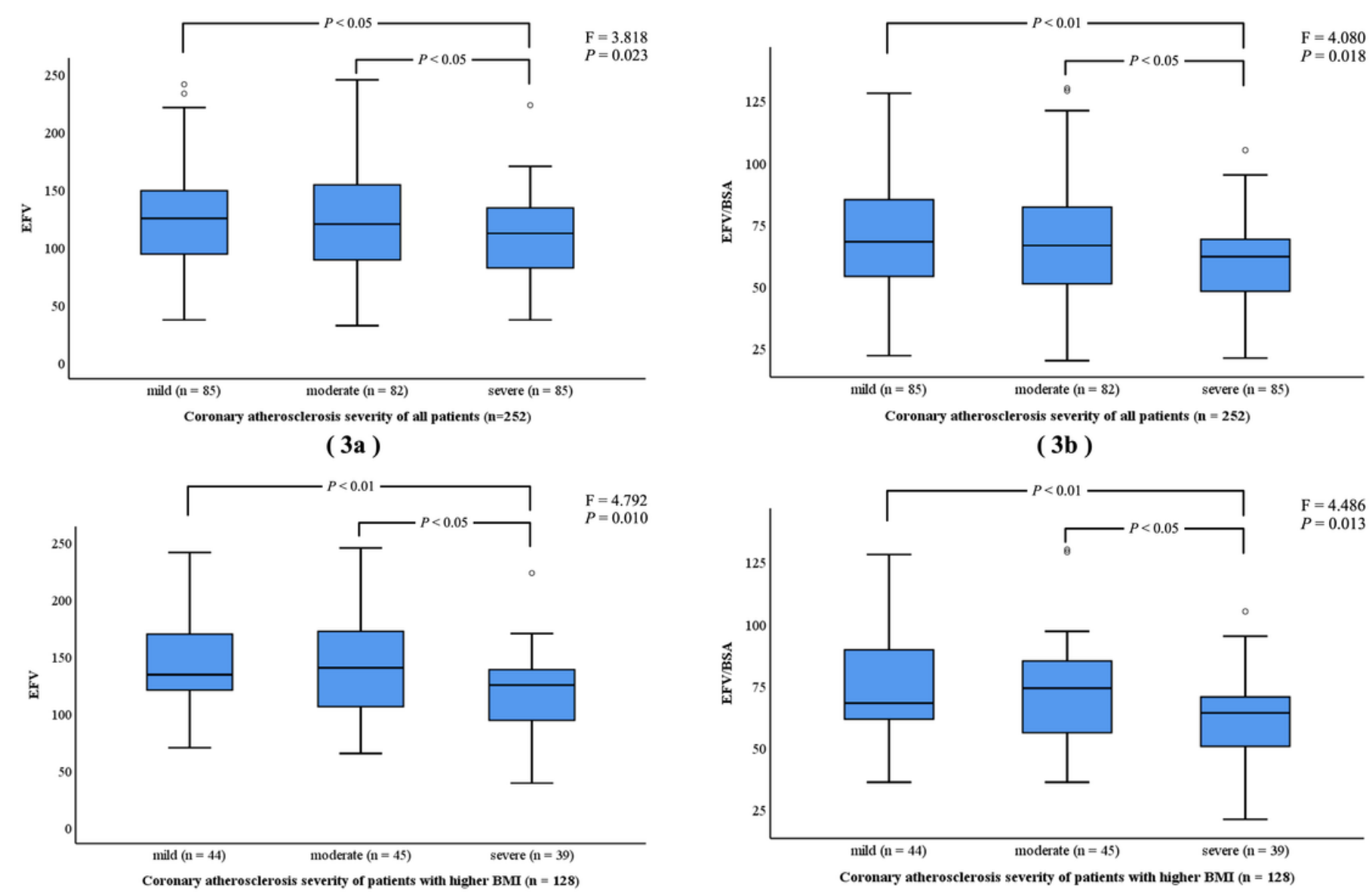

(3c)

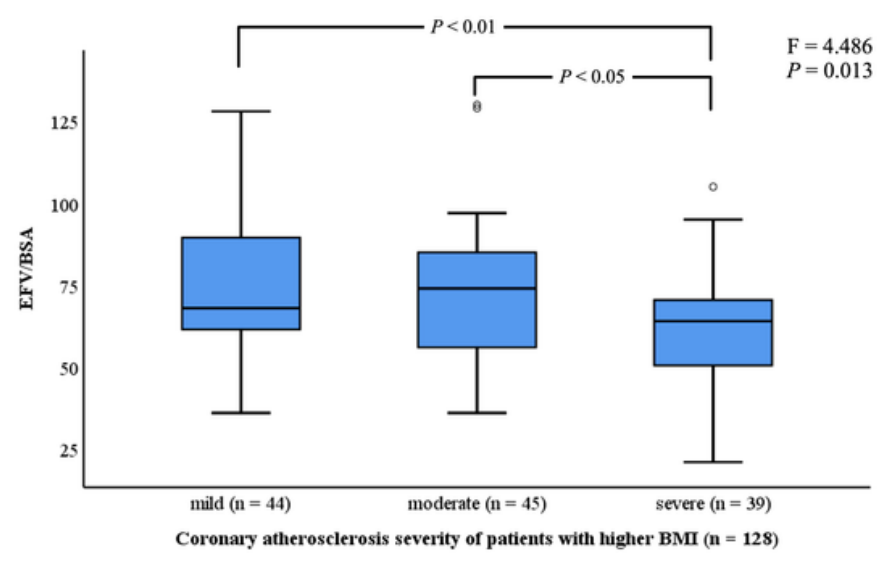

(3d)

Figure 3

Relation of EFV level to coronary atherosclerosis severity in three-vessel CAD

Three-vessel CAD patients with more severe coronary atherosclerosis have significantly lower EFV level $(\mathbf{3 a}, \mathbf{3 b})$, especially in those patients with higher BMI $\left(\geq 25 \mathrm{~kg} / \mathrm{m}^{2}\right)(\mathbf{3 c}, \mathbf{3 d})$.

EFV, epicardial fat volume; CAD, coronary artery disease; BMI, body mass index. 